\title{
The permanence of the client under uncertain estimations
}

\section{ABSTRACT}

Marketing has studied the permanence of a client within an enterprise because it is a key element in the study of the value (economic) of the client (CLV). The research that they have developed is based in deterministic or random models, which allowed estimating the permanence of the client, and the CLV.

However, when it is not possible to apply these schemes for not having the panel data that this model requires, the period of time of a client with the enterprise is uncertain data. We consider that the value of the current work is to have an alternative way to estimate the period of time with subjective information proper of the theory of uncertainty.

To achieve the above we propose, through a numerical example, a methodology that uses in its first phase the Fuzzy-Delphi method, with a group of experts, to acomplish an estimation of the lifetime period of the client within an enterprise, expressed as a trapezoidal fuzzy number, and to get a better consensus of the previous result, as a second phase, we submit such information to another group, different from the previous ones, obtaining a reduction of the size of the interval defined by the initial trapezoidal fuzzy number.

KeyWords: Customer value, Customer permanence, Delphi Method, Trapezoidal fuzzy numbers, Uncertainty, Experts.

\section{INTRODUCTION}

In the literature, the permanence or active life of a customer within an enterprise has been studied under different angles. For example, Grayson and Ambler (1999), based on previous studies of Moorman, Zaltman and Deshpandé (1992), argued that within the marketing of services the relationships between clients and enterprises, at the long term have a "dark side", which can provoke a reduction on the level of confidence in such relations.

On the other hand, Moorman, Zaltman and Deshpandé (1992) explain their results mentioning that there are dynamic factors that exist in long term relationships. For example: they argue that in lasting relationships each one of the parts acquires experience, which can provoke a loss of objectivity; besides, they justified that very long relationships can transform the perception of each one of the contraries as very similar between them, this can decrease the add value of the relation; another argument that they mention is that if the relationship of service between client and enterprise is sustained for a long term, this can lead to a mayor expectation on the service that they provide jeopardizing a bigger possibility of dissatisfaction; the authors mention that the clients can believe that the service provided in a long term relation, can take 
advantage in the confidence of one of the parts and act in an opportunistic way. As we can see, these arguments are the opposite to the main principles of the relational marketing.

In opposition to what is said in the previous paragraph, the study of the confidence in the relational marketing led to the theory named "The commitment-trust theory", developed by Morgan and Hunt (1994), taking this element as key on the success in long term relations. It's important to understand that the links established between clients and enterprises, will have different qualitative characteristics between those who are long term relations rather than the ones of short time, adjusting the best dynamic to each case.

Another point of view in the study of the permanence of the clients is the one who has to do with the benefits that they cause. Such line was developed by Reichheld and Sasser (1990), Reichheld (1993), (1994), (2002), and much more followers. They explain that the permanence of the client, generates four additional benefits to the profit basis, these are: revenue for sales increase due to customer spending often of cross and up-selling, for price premium extracted for value-added services, for operative costs reduction by improving the efficiency of serving customers, and revenues for referrals. However, Reinartz and Kumar (2000), have developed one of the most severe investigations in order to prove the weakness of the findings established by the line of Reichheld and his followers under a non-contractual setting, due to the fact that in this situation the customer can stop buying at any time because there's no document that compromises him to the enterprise.

With this different perspectives that we present in the study of the customer lifetime, we can see that time plays an important role if it's related to other variables, such as: added value, confidence, benefits, and some others.

This work will take as main element for analysis the time of permanence of a customer in a non-contractual setting, due that it's a key element in order to calculate the value (economic) of the customer (CLV). It must be mentioned that authors like Gil Lafuente, Ortigosa and Merigó (2007) and Gil Lafuente and Ortigosa (2009) presented the first models regarding the customer value under uncertainty in contractual settings where the variable of time is taken as a data in the certainty for being an established relation under a contract or agreement. In this cases uncertainty in relation to the validity of a customer as an active client or "live" client, is relatively null. We know that enterprises often use the so called exit barriers in order to keep the client until the contract expires. However, in several scenarios in real life there's no such contract or there are some type of agreements which the expiration date is not specified. For the above we'll treat the problem from the point in which the customer can become inactive at any moment in time, in this way uncertainty is present with more strength. 
To give an answer to the treatment of permanence of the client under uncertainty, a methodology will be proposed by using the Fuzzy-Delphi method developed by the professors Kaufmann y Gil Aluja (1986), asking the information through trapezoidal fuzzy numbers (TpFN) and improving the obtained information in that stage with a technique called "counter expertise".

\section{PREVIOUS CONSIDERATIONS TO THE PROPOSED METHODOLOGY: RANDOM AND UNCERTAINTY}

The words random and uncertainty frequently are terms used as synonymous, As for example authors like Pfeifer y Carraway (2000), in their customer value models, mentioned that they face uncertainty through the use of chains of Markov, other authors like Calciu (2009), developed stochastic models of the customer value assuming that such models are attached to certain laws of probability, leaving aside other marketing variables that can influence in the dynamic behavior of the consumer. Other authors like Kumar, et al. (2008) have developed proposals to calculate the value of a customer by adopting the model developed by Dwyer (1997) in which a client can purchase or not, in each period without fully leaving the relationship, this clients are called "always- ashare" where is assumed that a client never belongs only to one enterprise, rather they share their purchases, even if it's the same product with several enterprises. In the case of the CLV model developed by Kumar et al. (2008), three predictions are required: the quantity of marketing contacts directed to the client, the probability that one client purchase in each period and the economic contribution that each client generates in their purchase. With this sample of references we want to clarify that a lot of authors could face uncertainty through probabilistic, stochastic or random schemes. To avoid confusion in the current document, we considered convenient to point out that the term uncertainty has a very different meaning in this work. As a matter of fact uncertainty and random do not correspond to a same level of information.

When we say that a phenomenon has a random nature, we assure that is governed by the laws enunciated by Kolmogorov (1956). Random is linked to the concept of probability, which is a measure of repeatedly observations in time and space and developed in equal conditions; therefore, random is a measure of observed facts in the past, is totally objective. Instead, uncertainty doesn't have laws, is inefficiently structured and when tried to explain is in a subjective manner. Authors Kaufmann and Gil Aluja (1990) claim that an uncertain fact has the probability of development that cannot be situated in time and space, it refers to the future and the past doesn't contributes or gives very few information for the prevention of the event.

Gil Aluja (2002) mentions that when speaking of random, meaning, of probabilities and we're not able to justify them objectively or even vaguely, we're fooling ourselves. 
In the revised literature, we find instruments to predict the future purchase behavior patterns in consumers, which allow having one more element as an input in the estimation of the customer value (CLV). This facilitates the estimation of the life time or permanence of a client in an enterprise under probabilistic models. Proof of this is the Pareto model/NBD developed by Schmittlein, Morrison and Colombo (1987), whose purpose is to predict purchase patterns of a client within the active life in an enterprise; the name responds to several distributions of probability, giving as result that purchases have a Negative Binomial Distribution (NBD). This model was used by Reinartz and Kumar (2000) to determine, among other things, the probability that a client is active /alive in a future period. Despite of being a good model, due to is complexity to estimate certain parameters, its application is not easy in daily situations; therefore, the need to use as an alternative the BG/NBD model developed by Fader (2005), which is similar to the prior model and its application is easier; in this case, the initials responds to the distributions of probability involved: Beta Geometric and Negative Binomial Distribution once again.

To mention another example of this probabilistic models that allows to have the elements to estimate the CLV, is the Bayesian hierarchical model proposed by Borle (2008) where he estimates the CLV of each client in each purchase occasion using a joint model that includes the time of purchase, quantity of purchase and the risk of desertion of the client with the enterprise.

The sample of previous models reveals that the uncertainty treatment under random schemes prevails; reminding one more time that in this paper this term has a different meaning.

The new perspectives of the past decades in the scope of uncertainty allowed a new orientation to the scientific task, emerging some works based on the fuzzy subsets theory, which in other fields, the business management allowed a positive progress in formal developments. Due to this reasons, we're proposing an alternative solution in order to solve the problem to estimate the permanence or the life time period of a client under a non-contractual scheme, supported in the fuzzy subsets theory. The original contribution in this aspect lies in the fact of building an alternative path when we don't count with the data required by the random laws, neither the arguments related to them, meaning, the probabilistic models. In this way the lack of knowledge aims to fill the gap when we only have subjective information.

\section{METHODOLOGICAL PROPOSAL TO ESTIMATE THE DURATION OF THE CLIENT UNDER UNCERTAINTY}

Kaufmann and Gil Aluja (1992) established a clear difference between probability and possibility. They say that when a measure of probability is established, this is taken as objective and, therefore, is accepted by everybody. 
The notion of probability is linked to random and governed by its own laws. In this way when we use the term probable we associate to the notion of measure. Instead, the term of possibility, defined by the professor Lofti A. Zadeh introducer of the fuzzy idea in 1965, is one of many valuations proper of the theory of fuzzy subsets. A valuation is a subjective data supplied by one or several persons, each one of them immersed in its own circumstance. Therefore, when we use the term possible we associate to subjectivity in absence of an objective measure.

With this in mind, we analyze the permanence of a client within an enterprise in the scope of uncertainty, in situations in which probabilistic models cannot be used for several reasons, among them, the lack of objective information, poor structured information, incomplete information and many other reasons. For which we're using the traditional Delphi method, under the modality developed by Kaufmann and Gil Aluja (1986) named as Fuzzy-Delphi. Besides, as a result of the previous model and in order to decrease even more the level of uncertainty, we proposed the use of counter expertise with the intention of corroborating with other experts (different from the ones that participate with the Fuzzy-Delphi method) the observations made by the firsts. For this purpose, we briefly describe the conceptual elements and, with a numerical example, we present the methodology that we are proposing.

\subsection{Trapezoidal fuzzy numbers (TpFN) as information within the Fuzz- Delphi method}

We know that the Fuzzy-Delphi method originates within a group of investigators from the Rand Corporation of Santa Monica in the United States in the mid 70's, they ask to a group of experts about future dates of important projects, scientific and technical. Professors Kaufmann and Gil Aluja (1986) propose a modification to this method asking the information through fuzzy numbers in their different modalities; in our case we'll do it through trapezoidal fuzzy numbers (TpFN). With this methodology we'll be solving the problem of estimating the permanence (or time) of a client with an enterprise until a determine date. Even more, when we don't have adequate data that allow using the conventional methods proper of the random scope (probabilistic/statistic).

We start by reminding that a trapezoidal fuzzy number (TpFN) consists in the valuation of three values, in which the level of highest presumption is the interval of confidence, in this way, if $A=\left(a_{1} ;\left[a_{2} ; a_{3}\right] ; a_{4}\right)$ is an TpFN, then the

values won't be under $a_{1}$, not above $a_{4}$, the value of highest presumption is not a certain number as it happens with the triangular fuzzy numbers (TFN), is a confidence interval $\left[a_{2} ; a_{3}\right]$ and under the assumption of proportionality between this interval and the ends, we get the figure of a trapezoid, hence the name given to this fuzzy number (see Graphic 1). 


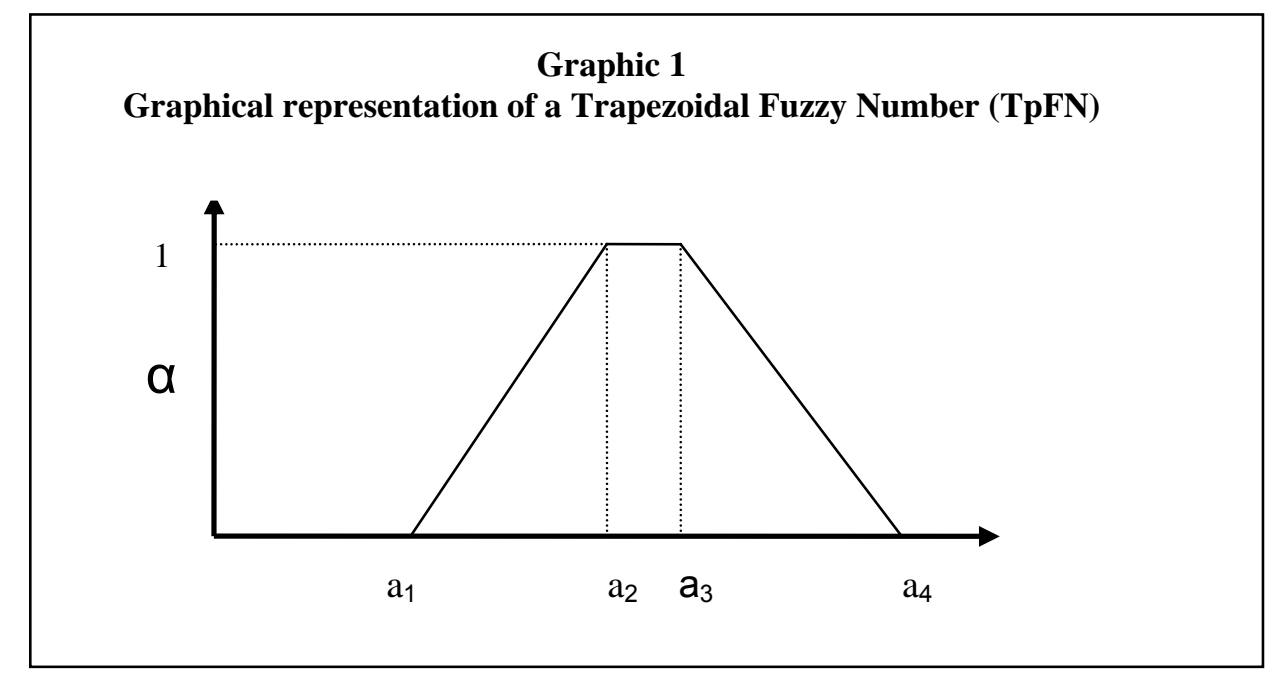

It's possible and happens in reality, that we don't know and cannot be estimated other presumptions than the ends of the two dimensions (inferior end $a_{1}$ and superior end $a_{4}$ ) having a zero level of presumption $(\alpha=0)$ is not credible that may occur and as an estimate of the maximum presumption $(\alpha=1)$ we give the liberty of expressing it as a confidence interval $\left[a_{2} ; a_{3}\right]$.

With this brief presentation of the TpFN, we're going to solve the problem of estimating the permanence of a client with the enterprise, when doesn't exist a contractual setting and we're not able to apply a scheme in the frame of probabilities.

The example that we are about to present will allow us to prove the utility of the Fuzzy-Delphi method (phase 1) and the use of the counter expertise with the $\mathrm{m}$ expertons (phase 2) in order to consensus even more the information given by the first experts. We must clarify, as the same authors mention Kaufmann and Gil Aluja (1993) that an expert in the context of the current work we understand as qualified persons, sometimes specialists, sometimes persons that possess knowledge in different fields. The authors says that the opinion of an expert can be directed to anything, concrete or abstract, an image, an object, a calculation, a theory, an idea, a behavior, among other things.

Example. As phase 1 of the methodological proposal is to use the Delphi method, For that, we assume that we are in conditions of gathering a group of five experts in order to take their opinions about the closest moment (not before) for a client definitely abandon the enterprise, the farthest moment (not after) for a client to definitely abandon an enterprise; and as mentioned when 
presented the TpFN in previous paragraphs, we're going to ask to this group of experts the confidence interval that represents the two moments considerate as the one of greatest possibility of abandon of the client (the maximum presumption).

In general we're talking of periods (or moments) of time to avoid specific dates, so that in these periods can be: days, weeks, months, years etc. according to the specific situation.

In this case the questions to the topic that matters to us can be:

- $\quad$ Can the closest period (or moment) can be estimate (not before) for the client to definitely abandon the enterprise?

- Can an interval of periods (or two moments) of highest possibility can be estimated for the client to definitely abandon the enterprise?

- $\quad$ Can the farthest period (or moment) can be estimate (not after) for the client to definitely abandon the enterprise?

Following, we present the results with our numerical example, considering that all the experts received the same information requested (see Frame 1).

\begin{tabular}{|c|c|c|c|}
\hline \multicolumn{4}{|c|}{ Frame 1 } \\
\hline Periods or moments (years, months, weeks, days, etc.)
\end{tabular}

Once this information is obtained by the experts that participate in the Delphi method, we proceed to calculate the mean trapezoidal fuzzy number:

$$
E_{\mathrm{TpFN}}=[15 / 5 ;[27 / 5 ; 41 / 5] ; 58 / 5]=[3 ;[5.4 ; 8.2] ; 11.6]
$$

In order to seek for the value that better represents the previous mean TpFN, we take this number to the deterministic scope, even when we loose information. For that, the arithmetic mean is calculated giving as usual the double of importance to the maximum presumption, which turns to be an interval, it is reduced to the deterministic scope in its mean-point. 
Development:

$[5.4 ; 8.2]$ reduced in the determinism is 6.8

$[3 ; 6.8 ; 11.6]$ reduced in the determinism is:

$$
\mathbf{E}_{\mathrm{TpFN}}=\frac{3+6.8+6.8+11.6}{4}=7.05
$$

Once we get the firsts information, we proceed to calculate the absolute deviation of the opinion of each expert in relation to the mean trapezoidal fuzzy number. For that we have the following result (see Frame 2)

\begin{tabular}{|c|c|c|c|c|}
\hline \multicolumn{5}{|c|}{$\begin{array}{c}\text { Frame } 2 \\
\text { Absolut deviations }\end{array}$} \\
\hline Experts & $\begin{array}{c}\begin{array}{c}\text { Desviation } \\
\text { left value }\end{array} \\
3-E_{\text {TpiFN }}\end{array}$ & $\begin{array}{c}\begin{array}{c}\text { Deviation left } \\
\text { value of the } \\
\text { interval of } \\
\text { maximum } \\
\text { presumption }\end{array} \\
5.4-E_{\text {TpiFN }}\end{array}$ & $\begin{array}{c}\text { Deviation } \\
\text { right value } \\
\text { of the } \\
\text { interval of } \\
\text { maximum } \\
\text { presumption } \\
8.2 \text { - } E_{\text {TpiFN }}\end{array}$ & $\begin{array}{c}\text { Deviation } \\
\text { right value }\end{array}$ \\
\hline 1 & 0 & 0.4 & 1.2 & 2.6 \\
\hline 2 & 1 & 1.4 & -0.8 & -0.4 \\
\hline 3 & 0 & 0.4 & 2.2 & 1.6 \\
\hline 4 & -1 & -0.6 & -1.8 & -1.4 \\
\hline 5 & 0 & -1.6 & -0.8 & -2.4 \\
\hline
\end{tabular}

With a quick inspection to Frame 2 we can observe that there are no meaningful differences, maybe a little in the deviation in the right value of maximum presumption of the expert 3 and in the deviations in the right value of expert 1 and 5 , however, if we consider the information as a whole, such deviations are not important. As indicated by the traditional Delphi method, it's recommended to show such deviations to each expert in an individual manner, in order to watch any possible change in any of them to calculate once again the deviations with the new information. For purposes of our example, we assume that all the experts confirm their opinion knowing the mean trapezoidal fuzzy number. Which means that we have just gather the information of the opinion of the five experts in relation to the permanence of the client at the enterprise, having a result of 7.05 periods.

Now we'll go to the phase 2 of our numerical exercise using the counter expertise and $\mathrm{m}$ - expertons. Such methodology is useful when we want to show 
the subjective information of several experts to another group of different experts having in mind the liberty that the second experts have in corroborating the initial information or it can be modified if it's necessary.

\subsection{The counter expertise and the m-expertons}

As a result of the previous exercise we have that the opinion of five experts gives the mean trapezoidal fuzzy number of:

$$
\mathrm{E}_{\mathrm{TpFN}}=[3 ;[5.4 ; 8.2] ; 11.6]
$$

In order to reach a more convincing result, we're going to use the "counter expertise" method. Since the intention is to corroborate with other experts the observations made by the first ones and thereby decrease the rank of uncertainty "compressing" the intervals that describes the previous mean TpFN. As in the current example, the estimations were expressed in triplets, where the value of the center, is in turn another confidence interval (of most presumption), in order to take advantage of this information, we are going to ask the counter experts their valuation in the form of confidence triplet in relation to both ends of the TpFN and the relative position of the maximum presumption, using the same hendecagonal scale. In this way we "compress" the end values from both sides, we compare the value of maximum presumption obtained by the counter experts and the original interval obtained by the first experts, in order to obtain the interval of periods of highest possibilities in the abandon of a client.

By asking the information to the counter experts in the form of confidence triplets, we can build the named m-expertons. Kaufmann and Gil Aluja (1992) they define an m-experton as an experton in which the values of trust are constituted by confidence triplets, where the maximum presumption can be an interval or a valuation.

For each level of presumption $\alpha$ we have:

$$
\left[a_{1}(\alpha) ;\left[a_{2}(\alpha) ; a_{3}(\alpha)\right] ; a_{4}(\alpha)\right]
$$

With: $0 \leq a_{1}(\alpha) \leq a_{2}(\alpha) \leq a_{3}(\alpha) \leq a_{4}(\alpha) \leq 1, \alpha \in\{0 ; 0.1 ; 0.2 ; \ldots 0.9$; 1\}

$a_{1}(\alpha)$ : is the smallest value accepted

$a_{4}(\alpha)$ : is the highest value accepted

$\left[a_{2}(\alpha) ; a_{3}(\alpha)\right]$ : is the confidence interval that corresponds to the maximum presumption

It can be variations where the confidence triplet is expressed with only one value of maximum presumption: 


$$
\left[a_{1}(\alpha) ;\left[a_{2}(\alpha)=a_{3}(\alpha)\right] ; a_{4}(\alpha)\right]=\left[a_{1}(\alpha) ; a_{3}(\alpha) ; a_{4}(\alpha)\right]
$$

or as only one interval :

$$
\left[a_{1}(\alpha)=a_{2}(\alpha) ; a_{3}(\alpha)=a_{4}(\alpha)\right]=\left[a_{1}(\alpha) ; a_{4}(\alpha)\right]
$$

or as only one valuation:

$$
\left[a_{1}(\alpha)=a_{2}(\alpha)=a_{3}(\alpha)=a_{4}(\alpha)\right]=a_{1}(\alpha)
$$

The previous authors mention that the m-expertons allow expressing their knowledge with greater sensibility. The algebra of the m-expertons matches with the experts, at the same time that establish a generalization to the expertons appreciation, when necessary. In our case though we want to take advantage from the first experts of the confidence interval of maximum presumption, we consider that this justifies the use of the m-expertons.

If the interval over which we are making the query is not suitable for being very reduced for one or several counter experts, these can propose new values and form a new value configured by the smallest value among the proposed ones and the highest value among the proposed: with this we are seeking to give more freedom of opinion to the experts. We'll assume, in our example, that everyone accepts without difficulty the end values of the mean trapezoidal fuzzy number $\mathrm{E}_{\mathrm{TpFN}}=$ [3; [5.4; 8.2]; 11.6].

With the purpose of confirming the observations made by the first experts, and if possible, decrease the amplitude of the intervals without losing information, we'll ask 5 counter experts, different from the previous ones, a valuation of the abandon of a client using the next hendecagonal scale and the interval on which the query formed by the ends of the mean trapezoidal fuzzy number $\mathrm{E}_{\text {TPFN },:}[3 ; 11.6]$.

$\sim$

$0 \quad$ : the abandon of the client takes place in 3 periods

0.1 : the abandon of the client takes place in practically 3 periods

0.2 : the abandon of the client takes place in almost 3 periods

0.3 : the abandon of the client takes place close to 3 periods

0.4 : the abandon of the client takes place closer to 3 than to 11.6 periods

0.5 : the abandon of the client takes places as close to 3 as to 11.6 periods

0.6 : the abandon of the client takes places closer to 11.6 than to 3 periods

0.7 : the abandon of the client takes place close to 11.6 periods

0.8 : the abandon of the client takes place in almost 11.6 periods

0.9 : the abandon of the client takes place in practically 11.6 periods

1 : the abandon of the client takes place in 11.6 periods 
Once we understand the semantic that we're using, we give to the counter experts a greater freedom to express their opinions regarding the interval, through the triplets of confidence which could be reduced to confidence intervals or even to valuations.

In this way, each counter expert provides a confidence triplet in $[0,1]$, meaning:

$$
\left[a_{1 i} ;\left[a_{2 i} ; a_{3 i}\right] ; a_{4 i}\right]
$$

With: $0 \leq a_{1 i} \leq a_{2 i} \leq a_{3 i} \leq a_{4 i} \leq 1$ to preserve the horizontal monotony, and where $a_{1 i} y a_{4 i}$ represent the opinion of the end values and, $\left[a_{2 i} ; a_{3 i}\right]$ the relative position to the confidence interval of maximum presumption.

Only as an example, if the counter expert issues its valuation with the triplet $[0.3 ; 0.6 ; 0.9]$ means that he thinks that "the abandon of the client takes place close to 3 periods" in the worst scenario; "the abandon of the client takes place in practically 11.6 periods" in the best scenario; but if he has reasons to think that the greatest possibility is when "the abandon of the client takes place closer to 11.6 than to 3 periods". Is possible that several experts reduce their opinions to one interval or to only one valuation; however the idea is to rescue the information that could emerge from the opinion of the maximum presumption under the form of a triplet.

To continue with our numerical example, suppose that the answers of the five counter experts are:

Counter expert $1:[0.3 ;[0.5 ; 0.6] ; 0.8]$

Counter expert 2: $[0.3 ; 0.6]$

Counter expert 3: 0.5

Counter expert $4:[0.4 ; 0.7 ; 0.9]$

Counter expert $5:[0.2 ; 0.5]$

From this information we build the m-experton. For this we follow the same process as with the experton, developing the next 3 steps:

1. Statistics or absolute frequencies

2. Relative frequencies or normalized

3. Accumulated complementary statistics (m-experton)

The previous three phases gives us the information frames that we present ahead.

To help us interpret more easily the m-experton we're going to obtain the expected value expressed in the lower part of the m-experton as follows:

$[1+1+0.8+0.4+0.2+0+0+0+0+0] 1 / 10=[3.4] 1 / 10=0.34$

$[1+1+0.8+0.6+0.6+0.2+0.2+0+0+0] 1 / 10=[4.4] 1 / 10=0.44$ 
$[1+1+1+1+1+0.6+0.2+0+0+0] 1 / 10=[5.8] 1 / 10=0.58$

$[1+1+1+1+1+0.6+0.4+0.4+0.2+0] 1 / 10=[6.6] 1 / 10=0.66$

We can see in the confidence triplet, where it summarizes the information contained in the m-experton, that the opinions are balanced around the 0.5 value. Therefore we can expect a reduction of the end values as well as the confidence interval of maximum presumption that form the original means $\mathrm{TpFN}$, thanks to the opinion of the counter experts.

To prove what we mentioned in the previous paragraph, is time to transform the valuations in $[0,1]$ developed by the counter experts in periods (or moments) of time, we are making reference to the $\mathrm{R}^{+}-\mathrm{m}$-expertons.

\begin{tabular}{|c|c|cc|c|}
\hline \multicolumn{5}{|c|}{ Statistics } \\
\hline 0 & & & & \\
\hline 0.1 & & & & \\
\hline 0.2 & 1 & 1 & & \\
\hline 0.3 & 2 & 1 & & \\
\hline 0.4 & 1 & & & \\
\hline 0.5 & 1 & 2 & 2 & 2 \\
\hline 0.6 & & & 2 & 1 \\
\hline 0.7 & & 1 & 1 & \\
\hline 0.8 & & & & 1 \\
\hline 0.9 & & & & 1 \\
\hline 1 & & & & \\
\hline
\end{tabular}

\begin{tabular}{|c|c|cc|c|}
\hline \multicolumn{5}{|c|}{ Relative Frequencies } \\
\hline 0 & & & & \\
\hline 0.1 & & & & \\
\hline 0.2 & 0.2 & 0.2 & & \\
\hline 0.3 & 0.4 & 0.2 & & \\
\hline 0.4 & 0.2 & & & \\
\hline 0.5 & 0.2 & 0.4 & 0.4 & 0.4 \\
\hline 0.6 & & & 0.4 & 0.2 \\
\hline 0.7 & & 0.2 & 0.2 & \\
\hline 0.8 & & & & 0.2 \\
\hline 0.9 & & & & 0.2 \\
\hline 1 & & & & \\
\hline
\end{tabular}

\begin{tabular}{|c|c|cc|c|}
\hline \multicolumn{6}{|c|}{ Accumulated Relative Frequencies } \\
\hline 0 & 1 & 1 & 1 & 1 \\
\hline 0.1 & 1 & 1 & 1 & 1 \\
\hline 0.2 & 1 & 1 & 1 & 1 \\
\hline 0.3 & 0.8 & 0.8 & 1 & 1 \\
\hline 0.4 & 0.4 & 0.6 & 1 & 1 \\
\hline 0.5 & 0.2 & 0.6 & 1 & 1 \\
\hline 0.6 & 0 & 0.2 & 0.6 & 0.6 \\
\hline 0.7 & 0 & 0.2 & 0.2 & 0.4 \\
\hline 0.8 & 0 & 0 & 0 & 0.4 \\
\hline 0.9 & 0 & 0 & 0 & 0.2 \\
\hline
\end{tabular}




\begin{tabular}{|l|l|ll|l|}
\hline 1 & 0 & 0 & 0 & 0 \\
\hline
\end{tabular}

m-experton $=$

$[0.34 ; \quad[0.44 ; 0.58] ; 0.66]$

Kaufmann and Gil Aluja (1993) mention that if an expert chooses an interval $\left[\alpha_{1} ; \alpha_{2}\right]$ for a valuation in the interval $\left[A_{*} ; A^{*}\right]$ similar to our problem, then it will correspond by linear transformation:

$$
\left[A_{1} ; A_{2}\right]=A *(+)\left(\left(A^{*}-A^{*}\right)(\bullet)\left[\alpha_{1} ; \alpha_{2}\right]\right)
$$

Applying the previous expression to $n$ experts, the formula is extensive to the $\mathrm{m}$-expertons in order to form the $\mathrm{R}^{+}$-m-expertons. Therefore, Kaufmann and Gil Aluja (1992) mention that a $\mathrm{R}^{+}$-m-experton is obtained by the following formula:

$$
R^{+}-\text {-experton }=A^{*}(+)\left(\left(A^{*}-A^{*}\right)(\cdot) \text { m-experton }\right)
$$

where $\left(A_{*}, A^{*}\right)$ is the interval to consider in the valuations.

To be more explicit, individually we have:

$$
\left[a_{i 1} ;\left[a_{i 2} ; a_{i 3}\right] ; a_{i 4}\right]=A_{*}(+)\left(\left(A^{*}-A_{*}\right)(\bullet)\left[\alpha_{i 1} ;\left[\alpha_{i 2} ; \alpha_{i 3}\right] ; \alpha_{i 4}\right]\right)
$$

where $\alpha_{i 1}, \alpha_{i 2}, \alpha_{i 3}, \alpha_{i 4}$ are the valuations issued by the counter expert $i$ and $a_{i 1}, a_{i 2}, a_{i 3}, a_{i 4}$ are the periods of time as a result of these valuations.

Applying the previous formula to our problem with the interval [3; 11.6]: and with the m-experton that we obtained, we have:

$$
\mathrm{R}^{+}-\mathrm{m} \text {-experton }=3(+)((11.6-3)(\bullet) \text { m-experton })
$$

Replacing we have:

\begin{tabular}{|c|c|cc|c|}
\hline \multicolumn{5}{|c|}{ m-experton } \\
\hline 0 & 1 & 1 & 1 & 1 \\
\hline 0.1 & 1 & 1 & 1 & 1 \\
\hline 0.2 & 1 & 1 & 1 & 1 \\
\hline 0.3 & 0.8 & 0.8 & 1 & 1 \\
\hline 0.4 & 0.4 & 0.6 & 1 & 1 \\
\hline 0.5 & 0.2 & 0.6 & 1 & 1 \\
\hline 0.6 & 0 & 0.2 & 0.6 & 0.6 \\
\hline
\end{tabular}




\begin{tabular}{|c|l|lc|c|}
\hline 0.7 & 0 & 0.2 & 0.2 & 0.4 \\
\hline 0.8 & 0 & 0 & 0 & 0.4 \\
\hline 0.9 & 0 & 0 & 0 & 0.2 \\
\hline 1 & 0 & 0 & 0 & 0 \\
\hline
\end{tabular}

0.66]

$[0.34 ;[0.44 ; 0.58]$

\begin{tabular}{|c|c|c|cc|c|}
\hline \multicolumn{5}{|c|}{$\mathrm{R}^{+}$-m-experton } \\
\cline { 2 - 6 } $\mathrm{R}^{+}$-m-experton $=$ & 11.6 & 11.6 & 11.6 & 11.6 \\
\cline { 2 - 6 } & 0.1 & 11.6 & 11.6 & 11.6 & 11.6 \\
\cline { 2 - 6 } & 0.2 & 11.6 & 11.6 & 11.6 & 11.6 \\
\cline { 2 - 6 } & 0.3 & 9.9 & 9.9 & 11.6 & 11.6 \\
\cline { 2 - 6 } & 0.4 & 6.4 & 8.2 & 11.6 & 11.6 \\
\cline { 2 - 6 } & 0.5 & 4.7 & 8.2 & 11.6 & 11.6 \\
\hline 0.6 & 3.0 & 4.7 & 8.16 & 8.2 \\
\hline 0.7 & 3.0 & 4.7 & 4.72 & 6.4 \\
\hline 0.8 & 3.0 & 3.0 & 3.0 & 6.4 \\
\hline 0.9 & 3.0 & 3.0 & 3.0 & 4.7 \\
\hline 1 & 3.0 & 3.0 & 3.0 & 3.0 \\
\hline
\end{tabular}

As predicted, we observed in the inferior part of the $\mathrm{R}^{+} \mathrm{m}$-experton, a considerable reduction in the values compared to the mean TpFN obtained through the fuzzy-delphi method:

$$
E_{\text {TpFN }}=[3 ;[5.4 ; 8.2] ; 11.6]
$$

In the ends, we obtained a reduction of $[3 ; 11.6]$ to $[5.9 ; 8.7]$. In relation to the intervals of maximum presumption, we propose the next general criteria to obtain the ultimate interval.

If $\left[b_{1} ; b_{2}\right]$ is the interval of maximum presumption obtained through the mean trapezoidal fuzzy number by the first experts and $\left[\mathrm{cb}_{1} ; \mathrm{cb}_{2}\right]$ is the interval obtained based on the valuation in $[0,1]$ of the counter experts, then:

Case 1. If $\left[b_{1} ; b_{2}\right] \cap\left[c_{1} ; c_{2}\right]=\varphi$ Review the opinion of both groups due to the great differences in the intervals of maximum presumption. We consider this case as atypical but since there's freedom of opinion of the experts it may occur. 
Case 2. If $\left[b_{1} ; b_{2}\right] \cap\left[\mathrm{cb}_{1} ; \mathrm{cb}_{2}\right] \neq \varphi$ Then in the proposed criteria we have to consider the intersection of the magnitudes or periods present in both intervals of confidence to keep the period of uncertainty of maximum presumption provided by the two groups of experts and counter experts.

In our numerical example we have:

$$
[5.4 ; 8.2] \cap[6.8 ; 8.0]=[6.8 ; 8.0]
$$

Therefore, in this particular case the result doesn't suffer any alteration of the counter expertise remaining the confidence triplet as:

$$
[5.9 ;[6.8 ; 8.0] ; 8.7]
$$

The previous triplet, under the hypothesis of proportionality between the maximum presumption and the ends values, gives us a graphical representation of the trapezoidal fuzzy number decreasing the uncertainty of the first experts, with the support of the counter expertise. Following we'll see graphically what we obtained (see Graphic 2).

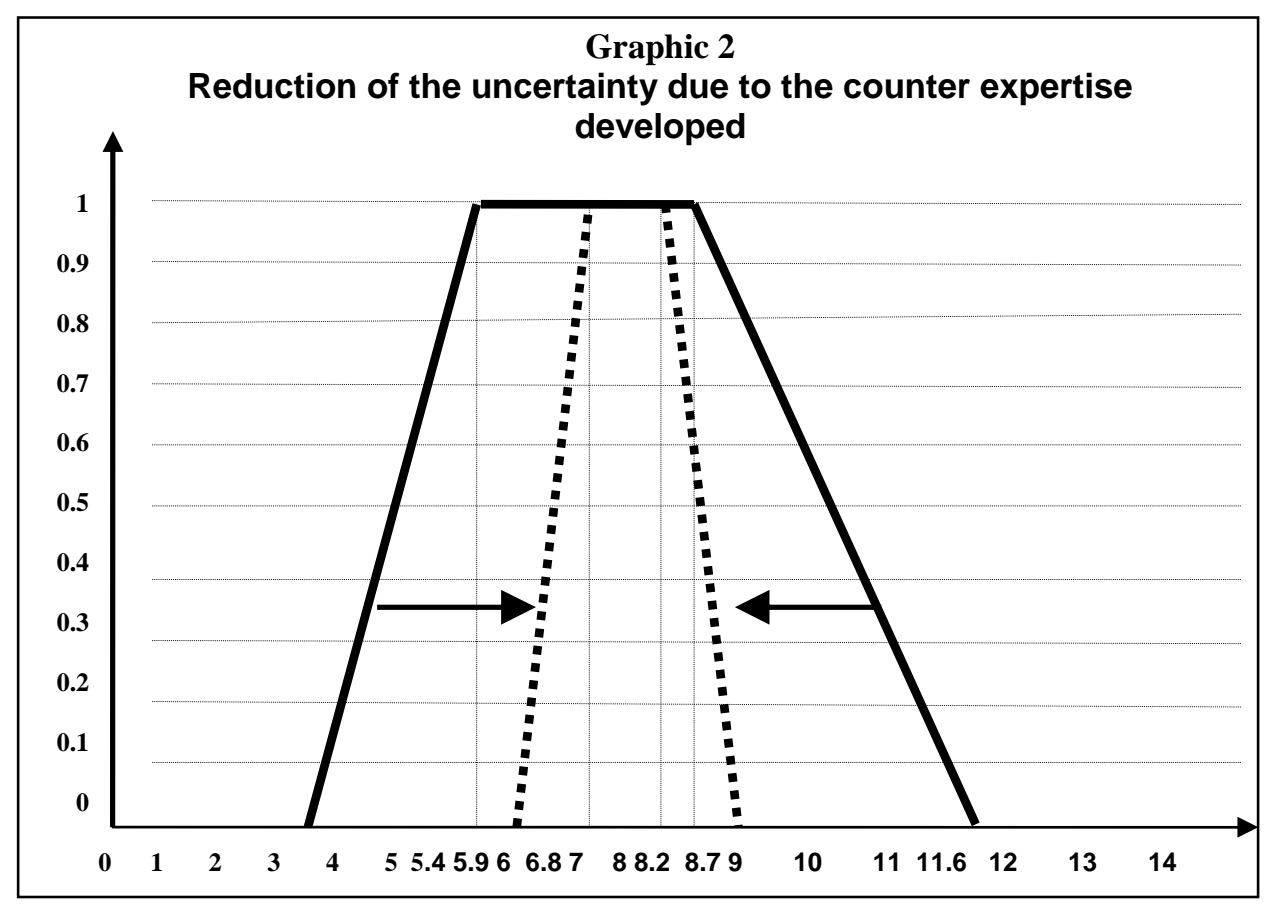

Frequently in these cases, we drop the entropy at the end in order to preserve all the information of our problem; In this case, this means to turn the mean 
confidence triplet in only one figure, reminding that the maximum presumption is taken into account twice. We have:

Of the interval of maximum presumption $[6.8 ; 8.0]$ the mean-point is: 7.4

Therefore, the average is: $\frac{5.9+7.4+7.4+8.7}{4}=7.35$

As the opinions of the experts and counter experts don't differ considerably, we can see that this result is very similar to the average of the TpFN in the determinism which the result was 7.05 . In this way we have that the possible time for a client to abandon the enterprise can be set in just over 7 periods.

\section{CONCLUSIONS}

One immediate conclusion with the example presented, is that only by asking one valuation to experts regarding the permanence of the client with an enterprise, under the form of a trapezoidal fuzzy number (TpFN), is possible to say that the client will abandon the enterprise in just over 7 periods. If we don't have data that the deterministic or random (probabilistic) schemes demands, then the previous data is satisfactory. It's important to point out that the information arises only from the subjective appreciations, but we insist, that they are very valuable for the so called experts.

A natural extension for this problem is to think that the request of the information about the permanence of the client with an enterprise can be developed through the so called random fuzzy subsets that are a generalization of the concept of the fuzzy subsets. In the Graphic 3 the traffic of the TpFN can be displayed to the random fuzzy subsets when requesting information from the experts about the permanence of the client with the enterprise under this format (see Graphic 3)

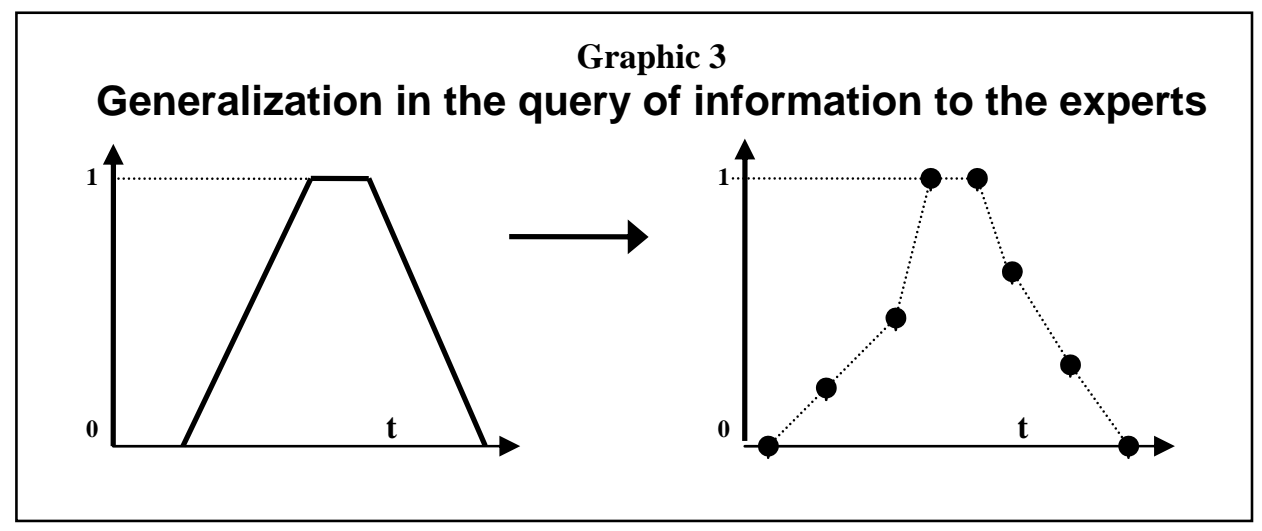


Finally, we mention that when there's little information or the information is incomplete, this is enough to inhibit the right use of the schemes already known in the scope of certainty or random.

\section{REFERENCES}

Borle, S., Singh, S.S., and Jain, D.C. (2008). "Customer Lifetime Value Measurement". Management Science. Vol.54 No.1, pp.100-112.

Calciu, M. (2009). "Deterministic and stochastic Customer Lifetime Value models. Evaluating the impact of ignored heterogeneity in noncontractual contexts". Journal of Targeting, Measurement, and Analysis for Marketing. Vol.17 No.4, pp. 257-271.

Dwyer, R.F. (1997). "Customer Lifetime Valuation to Support Marketing Decision Making". Journal of Direct Marketing. Vol. 11 No.4, pp. 6-13.

Fader, P. S., Hardie, B.G.S., and Lee, K. L. (2005). "Counting your Customer" the Easy Way: An Alternative to the Pareto/NBD Model". Marketing Science. Vol.24 No.2, pp. 275-284.

Gil Aluja, J. (2002). Introducción de la Teoría de la incertidumbre en la gestión de empresas. Vigo, Editorial Milladoiro.

Gil Lafuente, A.M., Ortigosa, M., and Merigó, J.M. (2007). "Teoría de la incertidumbre aplicada al valor del cliente en situaciones contractuales con intervalos de confianza". available at: http://www.upo.es/RevMetCuant/art15.pdf $\quad$ (accessed 11 December 2007).

Gil Lafuente, A.M., and Ortigosa, M. (2009). "El valor del cliente en relaciones contractuales con estimaciones inciertas". Revista de Administración, Finanzas y Economía. Vol. 3 No.2, pp. 91-110.

Grayson, K., and Ambler, T. (1999). "The dark Side of Long-Term Relationships in Marketing Services". Journal of Marketing Research. Vol. 36 No.1, pp. 132-141.

Kaufmann, A., and Gil Aluja, J. (1986). Introducción de la teoría de los subconjuntos borrosos a la gestión de las empresas. Santiago de Compostela, Editorial Milladoiro.

Kaufmann, A., and Gil Aluja, J. (1990). Las matemáticas del azar y de la incertidumbre: Elementos básicos para su aplicación en economía. Madrid, Editorial Centro de Estudios Ramon Areces.

Kaufmann, A., and Gil Aluja, J. (1992). Técnicas de gestión de empresa: Previsiones, Decisiones y Estrategias. Madrid, Ediciones Pirámide.

Kaufmann, A., and Gil Aluja, J. (1993). Técnicas especiales para la gestión de expertos. Vigo, Editorial Milladoiro.

Kolmogorov, A.N. (1956). Foundations of the theory of Probability. New York, Chelsea Publishing Company.

Kumar, V., Venkatesan, R., Bohling, T., and Beckmann, D. (2008). "The Power of CLV: Managing Customer Lifetime Value at IBM". Marketing Science. Vol. 27 No.4, pp. 585-589. 
Moorman, C., Zaltman, G., and Deshpandé, R. (1992). "Relationships Between Providers and Users of Market Research: The Dynamics of Trust within and Between Organizations". Journal of Marketing Research. Vol. 29 No.3, pp. 314-328.

Morgan, R.M., and Hunt, S. D. (1994). "The Commitment-Trust Theory of Relationship Marketing". Journal of Marketing. Vol. 58 No.3, pp. 20-38.

Pfeifer, P.E., and Carraway, R. L. (2000). "Modeling Customer Relationships as Markov Chains". Journal of Interactive Marketing. Vol.14 No.2, pp. 43-55.

Reichheld, F.F., and Sasser, W. E. Jr. (1990). "Zero Defections: Quality Comes to Services". Harvard Business Review. Vol.68 No. 5, pp.105 -111.

Reichheld, F.F. (1993). "Loyalty Based Management". Harvard Business Review. Vol.71 No. 2, pp. 64-73.

Reichheld, F.F. (1994). "Loyalty and the Renaissance of Marketing". Marketing Management. Vol. 2 No. 4, pp. 10- 21.

Reichheld, F.F. (2002). El efecto lealtad: Crecimiento, Beneficios y Valor último. Barcelona, Editorial Ariel.

Reinartz, W.J., and Kumar, V. (2000). "On the Profitability of Long-Life Customers in a Noncontractual Setting: An Empirical Investigation and Implications for Marketing". Journal of Marketing. Vol. 64 No. 4, pp. 1735.

Schmittlein, D.C., Morrison, D.G., and Colombo, R. (1987). "Counting your customers: Who are they and What will they do next?". Management Science. Vol.33 No.1, pp.1-24. 